2 http://dx.doi.org/10.2174/1574893609666140515230435

3

\title{
Metabolic control analysis and its applications
}

$9 \quad$ Ana Meireles ${ }^{1}$, Manuel Simões ${ }^{1 *}$

10

${ }^{1}$ LEPABE, Department of Chemical Engineering, Faculty of Engineering, University of Porto, Rua Dr. Roberto Frias, s/n, 4200-465 Porto, Portugal

*Author to whom correspondence should be addressed: Manuel Simões (mvs@fe.up.pt) 


\section{AbSTRACT}

2 Metabolic Engineering (ME) provides the know-how for the reconstruction of 3 microorganisms, in order to provide higher production rates of biotechnological 4 products and increase their potential application in several industries, particularly those 5 pharmaceutical, food and environmental. However, microbial metabolic cell

6 reconstruction has limitations. Metabolic Control Analysis (MCA) allows the evaluation

7 of the reliability of the changes performed by ME, emphasizing the importance of the

8 whole pathways rather than individual pathway reactions resulting from simple flux 9 analysis. This led to an increased emphasis on the regulatory structure of the network.

10 The use of MCA becomes indispensable to quantify metabolic parameters, particularly

11 those related with direct genetic modifications. However, this type of analysis is not a

12 common practice. In the present study MCA is exemplified as a tool of ME, being 13 demonstrated its practical application in drug delivery and in the production of three 14 relevant biotechnological products (penicillin V, l-lysine and glycerol).

16 Keywords: control coefficient, drug delivery, enzyme, glycerol, kinetics, 1-lysine, 17 metabolic control analysis, penicillin V. 
6-APA 6-aminopenicillanic acid

ACVS ACV synthetase

ADP Adenosine diphosphate

ASA Aspartate semialdehyde

ASD Aspartate semialdehyde dehydrogenase

ASK Aspartokinase

ASP L-aspartate

AT Acyl-CoA isopenicillin acyltransferase

ATP Adenosine triphosphate

BAP $\quad \beta$-aspartylphosphate

cys Cysteine

DAP D, L- diaminopimelate

DAPDC Diaminopimelate decarboxylase

DAPDH Diaminopimelate dehydrogenase

DHAP Dihydroxyacetone phosphate

DHP L-dihydrodipicolinate

DHPR Dihydrodipicolinate reductase

DHPS Dihydrodipicolinate synthase

FCC Flux control coefficient

glut Glutathione

GPD Glycerol-3-phosphate dehydrogenase

GPP Glycerol-3-phosphatase

IPN Isopenicillin N

IPNS Isopenicillin N synthetase

LLD-ACV L- $\alpha$-aminoadipyl-L-cysteinyl-D-valine 
Lys L-lysine

L- $\alpha$-AAA $\quad$ L- $\alpha$-aminoadipic acid

MCA Metabolic Control Analysis

ME Metabolic Engineering

MFA Metabolic Flux Analysis

NADPH Nicotinamide adenine dinucleotide phosphate

PERM Permease

$\mathrm{Pi} \quad$ Inorganic phosphate

Pyr Pyruvate

THDP L-tetrahydrodipicolinate

val Valine

1

2 LiST OF SYMBOLS

$\mathrm{c}_{\mathrm{i}} \quad$ Concentration of the i compound

$\mathrm{C}_{\mathrm{ij}}^{\mathrm{J0}} \quad$ Flux control coefficient for the $i$ th enzyme on $J$ th steady state flux

$\mathrm{C}_{\mathrm{ij}}^{\mathrm{x} 0} \quad$ Concentration control coefficient for the $i$ th enzyme on the $x$ th metabolite

$\mathrm{e}_{\mathrm{i}}^{0} \quad$ Enzymes activity through the $i$ th pathway

$\mathrm{J}_{\mathrm{i}}^{0} \quad$ Steady state flux through the $i$ th pathway

K Constant parameters

$\mathrm{K}_{\mathrm{eq}} \quad$ Equilibrium constant

$\mathrm{K}_{\mathrm{i}} \quad$ Inhibition constant

$\mathrm{K}_{\mathrm{m}} \quad$ Michaelis-Menten constant

L Lys-Thr Inhibition term by lysine and threonine

r Specific rate of the enzyme catalysed reaction

R Response coefficient

$\mathrm{R}_{\mathrm{ij}}^{\mathrm{J} 0} \quad$ Response coefficient for the $i$ th enzyme on $J$ th flux 
$\mathrm{R}_{\mathrm{ij}}^{\mathrm{x} 0} \quad$ Response coefficient for the $i$ th enzyme on the $x$ th metabolite

$v_{i} \quad$ Rate of an individual reaction

$v_{\max } \quad$ Maximum rate of the reaction

$\mathrm{x}_{\mathrm{i}}^{0} \quad$ Level of intracellular $i$ th metabolite

$\varepsilon \quad$ Elasticity coefficient

$\varepsilon_{\mathrm{ij}}^{\mathrm{c} 0} \quad$ Elasticity coefficients for the $i$ th enzyme related to external effectors

$\varepsilon_{\mathrm{ij}}^{\mathrm{e} 0} \quad$ Elasticity coefficients for the $i$ th enzyme related to enzyme activity

$\varepsilon_{\mathrm{ij}}^{\mathrm{x} 0} \quad$ Elasticity coefficients for the $i$ th enzyme related to intracellular metabolites

1

\section{1. INTRODUCTION}

3 The most interesting feature of organisms is their ability to perform a wide variety of

4 metabolic activities that provide the basis for synthesizing a wide range of products of

5 commercial value. However, in their natural environment, the metabolism of a living

6 cell is predominantly focused on survival and reproduction. In general, this means that

7 cells use their biochemical machinery to synthesize metabolites and cellular

8 constituents, in the minimum quantities required for their maintenance and growth.

9 However, the requirements of a biotechnological process are contrary to these facts, as a

10 compound of interest must be produced in large quantities in a way that the process is

11 profitable [1,2]. The study of cellular metabolism is a relevant strategy to understand

12 the unique properties and behaviour of the constituent elements, particularly enzymes

13 and their reactions. This has led to the continuous and growing interest of academic and

14 industry researchers in Metabolic Engineering (ME) [3, 4].

15 ME is based on the manipulation of the cellular metabolism in order to obtain an 16 organism capable of synthesizing a product of interest, at the maximum production rate,

17 requiring the minimal amount of substrate, and therefore, providing less expensive 
1 products [5-7]. ME is multidisciplinary and uses different knowledge from different 2 areas, such as Genetics, Mathematics, Computer Science, Biochemistry, among others

3 (Figure 1). To achieve the desired goals, microorganisms can be redesigned, to a certain

4 limit, modifying the existing metabolic pathways or inserting new paths $[8,9]$. If the

5 metabolic main components are identified, the manipulation of these components and

6 the study of the metabolic fluxes can be analysed, but not fully constructed. As genetic

7 modifications are not predictable, the random modification in a gene is not a sufficient

8 strategy to achieve a particular purpose. Therefore, it is necessary to understand the

9 subsequent interactions of this genetic manipulation on the microbial physiology and

10 behaviour [6]. Moreover, to make the desired changes, the knowledge of

11 Transcriptomics, Proteomics, Metabolomics and Fluxomics is essential information $12[10]$

13 After disrupting the natural system of organisms, research and experiments are still needed, to determine how to adjust the metabolic processes according to the manipulations. This process is a continuous and constructive cycle that permits to acquire more information every time a cycle is completed $[1,11]$.

ME involves mechanisms of analysis and synthesis. Therefore, ME focuses on kinetics, enzymatic catalysis and in stoichiometry reactions $[6,12]$. The enzymatic profile is crucial in identifying the steps that origin the desired product. ME defines the steps that contribute most to the development of the final product; which are the limiting steps (analysis); and executes the changes (synthesis) to achieve the desired objective [6]. The determination of metabolic fluxes is carried out by Metabolic Flux Analysis (MFA). The fluxes are considered the key element of metabolism and this analysis is strategic, since the fluxes contain the minimum information necessary to describe the metabolism $[2,6,10]$. 
1 Metabolic Control Analysis (MCA) can quantify the metabolic fluxes, that are

2 nonetheless than the rate of components production in the metabolic pathway [12].

3 MCA can help the manipulation of certain pathways in order to access the control that

4 an enzyme exerts in the fluxes [13]. The software available for MCA are typical tools

5 that can be applied in ME, such as CellDesigner, Wolfram Mathematica, Matlab, The R

6 Project for Statistical Computing [4, 14-16]. However, there are specific metabolic

7 simulators, such as SCAMP [17], MetaModel [18], Gepasi [19, 20], as well as MCA

8 coefficients calculators, like CONTROL [21] and MetaCon [22].

\section{MCA GUIDE}

The biochemical pathways of microorganisms are not yet fully understood, mainly due to the fact that the methods applied to uncover the biochemical systems are minimalists, regarding the representation of the complexity of metabolic pathways and their intervenients $[23,24]$. Therefore, there are mathematical methods, such as MCA, that are used to characterise and quantify the flux changes, by acting as a control. A MCA approach allows the quantification of cellular changes that may occur: metabolite concentration variation; changes in metabolic fluxes in response to changes in growth conditions; and enzyme activity (Figure 2) [25].

The concepts used in MCA have some gaps: they focus on the regulation of metabolic flux in an enzyme, and this cannot be considered absolutely correct, since the enzyme may not exercise control over the complete metabolic pathway. Despite the fact that a cell directs its machinery to regulate a particular enzyme, it does not mean that an increase or decrease in its activity will affect the flux significantly, the rate of the reaction can be affected by other factors, such as environmental, physiological or genetic [12]. Another disadvantage of this theory lies in the fact that there is not 
1 sufficient knowledge about enzyme kinetics, genetics, epigenetics and response to

2 environmental changes. This gap led to the development of various computational tools

3 that allow the study of metabolism, due to the variation of certain on and the

4 determination of the variables involved $[4,26]$.

5 Despite the limitations, this type of analysis is an advantageous tool for controlling the 6 metabolic flux of individual reactions and allows the verification of different 7 concentrations of intracellular metabolites and the enzyme activity [12].

8 MCA is only applied to reactions in the steady state or pseudo-stationary state [27]. It is

9 considered that the reactions studied are defined only by the activity of enzymes that act 10 at different stages of the pathway [12]. There are databases, such as MetaCyc 11 (www.metacyc.com) and BioCyc (www.biocyc.com) where all the information about 12 the metabolic pathways and enzymes can be accessed [28].

13 The enzyme kinetics is crucial to apply MCA [29]. It is necessary to determine the metabolic control coefficients: control and elasticity coefficients (which are interrelated) [27]. Therefore, MCA defines the quantitative relationship between the flux of a metabolic pathway, and the activity of an enzyme, in terms of flux control coefficient

17 (FCC) [30]. Consequently, FCC evaluates the influence of an enzyme in the pathway 18 flux [25].

19 The control coefficient allows the characterization of the systemic response of the system variables, such as metabolic flux and/or the concentration of metabolites. It correlates the changes observed with the disturbances imposed. The variation of the rate

22 of a single step reaction, regarding a metabolite, is expressed by the elasticity coefficient $[25,31,32]$. 
1 These coefficients are dimensionless [25] and are associated with the enzymes activities

$2\left(\mathrm{e}_{\mathrm{j}}^{0}\right)$, fluxes $\left(\mathrm{J}_{\mathrm{i}}^{0}\right)$, levels of intracellular metabolites $\left(\mathrm{x}_{\mathrm{i}}^{0}\right)$ and external factors $\left(\mathrm{c}_{\mathrm{i}}^{0}\right)$. The $3 \quad$ FCC's $\left(\mathrm{C}_{\mathrm{ij}}^{\mathrm{J0}}\right)$ can be calculated from equation 1 [33].

4

5

$$
C_{i j}^{J 0}=\frac{e_{j}^{0}}{J_{i}^{0}} \frac{d J_{i}}{d e_{j}}
$$

$6 \quad$ Where $\mathrm{C}_{\mathrm{ij}}^{\mathrm{J0}}$ is the FCC for the $i$ th enzyme on $\mathrm{J}$ flux [33].

7 This coefficient is considered the most important of the control coefficients and for a

8 linear pathway, has values between 0 and 1 . The enzyme that has the higher value of

$9 \quad$ FCC is the enzyme that has a higher flux control and an increase in this enzyme activity

10 will result in the flux increase $[12,34]$.

11 The concentration control coefficients $\left(\mathrm{C}_{\mathrm{ij}}^{\mathrm{x} 0}\right)$ are determined by equation $2[12,33,35]$.

$$
C_{i j}^{x 0}=\frac{e_{j}^{0}}{x_{i}^{0}} \frac{d x_{i}}{d e_{j}}
$$

14 Where $\mathrm{C}_{\mathrm{ij}}^{\mathrm{x} 0}$ is the concentration control coefficient for the $i$ th enzyme on the $\mathrm{x}$ 15 metabolite; $x_{i}^{0}$ are the levels of intracellular metabolites [12].

16 The elasticity coefficients $(\varepsilon)$ can be calculated from equations 3,4 and 5 , related to 17 intracellular metabolites $\left(\varepsilon_{\mathrm{ij}}^{\mathrm{x} 0}\right)$, enzyme activity $\left(\varepsilon_{\mathrm{ij}}^{\mathrm{e} 0}\right)$ and external effectors $\left(\varepsilon_{\mathrm{ij}}^{\mathrm{c} 0}\right)$, 18 respectively, as in any compound that modifies the reaction rate [12, 33].

19

20

$$
\varepsilon_{\mathrm{ij}}^{\mathrm{x} 0}=\frac{\mathrm{x}_{\mathrm{j}}^{0}}{\mathrm{~J}_{\mathrm{i}}^{0}} \frac{\partial v_{\mathrm{i}}}{\partial \mathrm{x}_{\mathrm{j}}}
$$

$$
\varepsilon_{\mathrm{ij}}^{\mathrm{e} 0}=\frac{\mathrm{e}_{\mathrm{j}}^{0}}{\mathrm{~J}_{\mathrm{i}}^{0}} \frac{\partial v_{\mathrm{i}}}{\partial \mathrm{e}_{\mathrm{j}}}
$$




$$
\varepsilon_{\mathrm{ij}}^{\mathrm{c} 0}=\frac{\mathrm{c}_{\mathrm{j}}^{0}}{\mathrm{~J}_{\mathrm{i}}^{0}} \frac{\partial v_{\mathrm{i}}}{\partial \mathrm{c}_{\mathrm{j}}}
$$

3 Where $v_{i}$ represents the rate of an individual reaction, $\varepsilon_{\mathrm{ij}}^{\mathrm{x} 0}$ the elasticity coefficient for

4 the $i$ th enzyme related to intracellular metabolites, $\varepsilon_{\mathrm{ij}}^{\mathrm{e} 0}$ the elasticity coefficients for the

$5 \quad i$ th enzyme related to enzyme activity and $\varepsilon_{\mathrm{ij}}^{\mathrm{co}}$ the elasticity coefficients for the $i$ th

6 enzyme related to external effectors $[12,33]$.

7 The response coefficients $(\mathrm{R})$ can also be defined, allowing to verify the effect of a 8 change in an external parameter. For the fluxes is set equation 6 , and for the 9 concentration is established equation $7[33,35]$.

$$
\mathrm{R}_{\mathrm{ij}}^{\mathrm{J} 0}=\frac{\mathrm{c}_{\mathrm{j}}^{0}}{\mathrm{~J}_{\mathrm{i}}^{0}} \frac{\mathrm{dJ}}{\mathrm{dc} \mathrm{c}_{\mathrm{j}}}
$$

$$
\mathrm{R}_{\mathrm{ij}}^{\mathrm{x} 0}=\frac{\mathrm{c}_{\mathrm{j}}^{0}}{\mathrm{x}_{\mathrm{i}}^{0}} \frac{\mathrm{dx}_{\mathrm{i}}}{\mathrm{dc} \mathrm{c}_{\mathrm{j}}}
$$

13 Where $\mathrm{R}_{\mathrm{ij}}^{\mathrm{J} 0}$ is the response coefficient for the $i$ th enzyme on $\mathrm{J}$ flux and $\mathrm{R}_{\mathrm{ij}}^{\mathrm{x} 0}$ is the response 14 coefficient for the $i$ th enzyme on the x metabolite [33, 35].

15 The elasticity coefficients are local properties, and take into account the variation of one effect (keeping the others constant), while the response coefficients are global, and 17 evaluate all the effects imposed [33]. On the other hand the control coefficients have 18 systemic properties and can only be compared with the control coefficients of the same 19 metabolic pathway [12].

20 Two theorems of flux control were introduced in detail by Stephanopoulos et al. [12]:

21 the Summation Theorem and the Connectivity Theorem [12, 33, 36]. For the 
1 Summation Theorem, the control of a metabolic pathway is distributed by the enzymes

2 that constitute it. This means that the sum of fluxes must be equal to one (equation 8)

$3 \quad[12,33,34]$.

4

$$
\sum C_{i j}^{j 0}=1
$$

5

6 If the pathway is very long, the FCC's will have a small value, but there has to be a

7 particular step in the pathway that exerts the control over the fluxes, if the FCC value is

8 considerably higher than the others. The FCC's with a small value, in a long pathway,

9 are the explanation for the numerous and consecutive mutations required to improve

strains to increase the production of selected metabolites [12].

11 Additionally, it is perceptible that one of the enzymes in the reaction has to exert negative control over the metabolites. Picturing a simple reaction, if the level of the enzyme increases and the metabolite concentration decreases the sum of the concentration control coefficients is zero (equation 9) [12, 33, 36].

$$
\sum C_{i j}^{x 0}=0
$$

The response coefficient can be calculated by the multiplication of FCC's and elasticity coefficients of the same enzyme (equation 10$)[12,33]$.

$$
\mathrm{R}_{\mathrm{ij}}^{\mathrm{J} 0}=\mathrm{C}_{\mathrm{ij}}^{\mathrm{J} 0} \cdot \varepsilon_{\mathrm{ij}}^{\mathrm{x} 0}
$$

21 When the action of more than one enzyme is present, it is used the sum of responses for each enzyme (equation 11) [12,33]. 


$$
\mathrm{R}_{\mathrm{ij}}^{\mathrm{J} 0}=\sum \mathrm{C}_{\mathrm{ij}}^{\mathrm{J0}} \cdot \varepsilon_{\mathrm{ij}}^{\mathrm{x} 0}
$$

1

2 The elasticity is related to flux control through the Connectivity Theorem presented in 3 its mathematical form in equation $12[12,33]$.

4

5

6 This theorem shows how the enzyme kinetics affects the flux control $[12,33]$. Higher

7 values of elasticity are reflected in lower FCC's. This gives an indication if the flux

8 control of certain reactions will be low or high, according to the elasticity [12, 33, 37].

9 For example, to block a pathway of a pathogen is important to identify which enzymes have the highest FCC's values. It is supposed that the inhibition of these enzymes reduces the flux of the pathway, controlling the pathogen proliferation [31].

The control coefficients can be determined by direct methods (titration with specific inhibitors, or genetic alteration of enzyme activity) or by indirect methods (SCAMP [17], MetaModel [18], Gepasi [19, 20]) and the elasticity coefficients can be calculated from kinetic models [12, 38], such as MetaCon [22] and CONTROL [21]. This software is based on the matrix method, therefore, it allows the determination of the matrix in a more simple approach than what was previously demonstrated [39].

\section{MCA SuCCESSFUl APPLiCATIONS}

The practical applications of MCA are mainly related with the medical field, allowing diagnose of diseases that are related to enzyme deficiencies by the identification of the cause of the metabolic pathway malfunction [40,41]. MCA also allows the deletion of specific metabolic pathways in pathogens [31] and is applied to the study of cancer treatment [42] and drug delivery [43], which are described below. 
1 Since the industry is interested in obtaining large quantities of particular

2 biotechnological products, penicillin-V, 1-lysine and glycerol were selected for this

3 study as cases of MCA successful applications [12, 23].

5

6

7

8

9 In order to a drug be delivered properly, the targeting is essential. To determine if the

\subsection{DRUG DELIVERY}

The drug delivery is an important pharmacology issue both quantitatively and qualitatively. MCA can be valuable to quantify and determine which components are more important for the functioning of the system [40, 44].

target is the most appropriate, one can use the control coefficients information. A good target is the one with the highest value of control coefficients [44].

In the case of cancer, the targeting is very important due to the fact that tumour cells are very similar to the non-tumour cells [44]. The conventional treatments are based in the tumour cells susceptibility towards irradiation and chemical compounds. The main problem with these treatments is the fact that it is not specific and it also affects the nontumour cells. These solutions can also lead to resistant tumour cells due to mutation. With these problems new solutions are being developed. In this way, MCA is a very important tool, since it permits to follow which reactions are controlling the processes. This control is not uniform and it belongs to multiple enzymes, which means that inhibiting or altering more than one enzyme is more efficient $[42,45]$. In other words, the rate limiting step is not a single step, but multiple steps, since the enzymes share the control of energy metabolism [42].

Özbayraktar and Ülgen [43] used two computational methods (MCA and metabolic pathway analysis) with the purpose of identifying enzymes of the sphingolipid pathway, which can be used as targets in the cancer therapy. Sphingolipids are a very important 
1 piece in cancer development and treatment. The metabolic significant reactions were

2 identified by MCA and the target enzymes, responsible for these reactions, were

3 selected and manipulated to accumulate ceramide - simple sphingolipid that induces

4 apoptotic responses. These authors propose the increasing activity of certain enzymes

5 (glycerol-3-phosphate, 4-hydroxylase, ceramide synthase, acetyl-coenzyme A

6 synthetase, etc.) and the decreasing activity of others (phosphoserine-phosphatase,

7 serine palmitoyltransferase, sphingolipid long chain base kinase, etc.) resulting in a

8 multiple response [43].

9 Type 2 diabetes mellitus is another disease where MCA was already used to identify 10 therapeutics strategies. Trombetta et al. [46] applied MCA to quantify the control 11 coefficients in the intravenous glucose tolerance test. This test evaluates the plasma glucose concentration and is used to diagnose the disease. The strategy was to target the points with highest control coefficients and restore the primary control [46].

\subsection{PENICILLIN V PRODUCTION}

An example of MCA application is the penicillin V (phenoxymethylpenicillin)

17 production by Penicillium chrysogenum. The $\beta$-lactam antibiotics are used to treat 18 various infectious diseases and, therefore, it becomes imperative to optimize the industrial production, being inevitable the application of ME [47-50].

The metabolic pathway of biosynthesis of penicillin V (Fig. 3) has three enzymatic

21 steps. The first step is the condensation of three amino acids: L- $\alpha$-aminoadipic acid (L$\alpha$-AAA), L-cysteine and L-valine, forming L- $\alpha$-aminoadipyl-L-cysteinyl-D-valine 23 (LLD-ACV). This first reaction is catalysed by the enzyme ACV synthetase (ACVS).

24 This enzyme also modifies the L-valine into D-valine running an epimerization [47, 49]. 
1 In the second step, the ring of LLD-ACV is closed. This reaction is catalysed by

2 isopenicillin $\mathrm{N}$ synthetase (IPNS) in the presence of oxygen, forming the isopenicillin $\mathrm{N}$ 3 (IPN) [47, 49].

4 The last step can occur in two different ways: two-step reaction and one-step reaction.

5 In the two-step reaction, the molecule of L- $\alpha$-AAA of IPN is cleaved and 6-

6 aminopenicillanic acid (6-APA) is released. If available a precursor phenoxyacetyl-CoA

7 is available, it can bind to the enzyme acyl-CoA isopenicillin acyltransferase (AT) and

8 turn into penicillin $\mathrm{V}$ [11]. In the reaction with only one step, the hydrophilic chain of

9 L- $\alpha$-AAA of IPN is exchanged for an added precursor (phenoxyacetic acid), resulting in

10 penicillin V, without release of 6-APA [47, 49].

11 The molecule of L- $\alpha$-AAA is released and can be reused for the synthesis of LLD-ACV.

12 However, part of this molecule undergoes cyclization to form 6-oxopiperide-2carboxylic acid which is excreted into the medium, with consumption of L- $\alpha$-AAA, implying that this molecule (L- $\alpha$-AAA) should be replaced during the biosynthesis of penicillin V [50].

This pathway has negative feedback inhibition by the first enzyme (ACVS) through the LLD-ACV. Therefore, to obtain a high production of penicillin $\mathrm{V}$, it becomes obvious that it is important to keep the concentration of LLD-ACV low, in order that the flux of production becomes higher, and that through the enzyme IPNS (which consumes LLD$\mathrm{ACV}$ ) there is a metabolic flux control [50].

According to different authors, the kinetic expressions are only projected to ACVS and IPNS, due to the greatest control of metabolic flux of these enzymes [12, 49, 51-54]. For ACVS, for the production of LLD-ACV, it was found that it follows the MichaelisMenten kinetics, resulting in the equation 13. 
$\mathrm{r}_{\mathrm{LLD}-\mathrm{ACV}}^{\mathrm{ACVS}}=\frac{v_{\max }}{1+\mathrm{K}_{\mathrm{L}-\alpha-\mathrm{AAA}} \cdot \mathrm{c}_{\mathrm{L}-\alpha-\mathrm{AAA}}^{-1}+\mathrm{K}_{\mathrm{cys}} \cdot \mathrm{c}_{\mathrm{cys}}^{-1}+\mathrm{K}_{\mathrm{val}} \cdot \mathrm{c}_{\mathrm{val}}^{-1}} \times \frac{1}{1+\mathrm{K}_{\mathrm{LLD}-\mathrm{ACV}}^{-1} \cdot \mathrm{c}_{\mathrm{LLD}-\mathrm{ACV}}}$

1

2 Where $\mathrm{r}$ is the specific rate of the enzyme catalysed reaction, $v_{\max }$ represents the 3 maximum rate of the reaction, $\mathrm{K}$ are constant parameters related to the compounds ( $\mathrm{L}$ $\alpha$-AAA, cysteine, valine and LLD-ACV) and $\mathrm{c}_{\mathrm{i}}$ refers to the concentration of the $i$ th compound (L- $\alpha$-AAA, cysteine, valine and LLD-ACV).

Regarding IPNS, for the production of IPN, is applied by equation 14 [12].

$$
\mathrm{r}_{\mathrm{LLD}-\mathrm{ACV}}^{\mathrm{IPNS}}=\frac{v_{\max } \cdot \mathrm{c}_{\mathrm{LLD}-\mathrm{ACV}}}{\mathrm{c}_{\mathrm{LLD}-\mathrm{ACV}}+\mathrm{K}_{\mathrm{m}}\left(1+\mathrm{c}_{\mathrm{glut}} \mathrm{K}_{\mathrm{i}}^{-1}\right)}
$$

Where $\mathrm{K}_{\mathrm{m}}$ is the Michaelis-Menten constant [12].

For the elasticity coefficients, the expressions that allow their determination are given by equations 15 and $16[53]$.

$$
\varepsilon_{\mathrm{LLD}-\mathrm{ACV}}^{\mathrm{ACVV}}=-\frac{\mathrm{K}_{\mathrm{LLD}-\mathrm{ACV}}^{-1} \cdot \mathrm{c}_{\mathrm{LLD}-\mathrm{ACV}}}{1+\mathrm{K}_{\mathrm{LLD}-\mathrm{ACV}}^{-1} \cdot \mathrm{c}_{\mathrm{LLD}-\mathrm{ACV}}}
$$

$$
\varepsilon_{\mathrm{LLD}-\mathrm{ACV}}^{\mathrm{IPNS}}=\frac{\mathrm{K}_{\mathrm{m}}\left(1+\mathrm{c}_{\text {glut }} \mathrm{K}_{\mathrm{i}}^{-1}\right)}{\mathrm{c}_{\mathrm{LLD}-\mathrm{ACV}}+\mathrm{K}_{\mathrm{m}}\left(1+\mathrm{c}_{\text {glut }} \mathrm{K}_{\mathrm{i}}^{-1}\right)}
$$

There are several published studies in which genetic engineering is applied to increase the productivity of penicillin $\mathrm{V}[47,49,55,56]$. However, there are no published works, other than those mentioned previously [12, 49, 51-54], using MCA to analyse the metabolic pathway and assess possible changes to be implemented.

\subsection{L-LYSINE PRODUCTION}

Lysine is an essential amino acid that has applications in the pharmaceutical area, as well as in feed and food products [57, 58]. Many studies have been made with the 
1 purpose of optimizing lysine production. In spite of this advances, it has not been found

2 a modified microorganism providing better results than the traditional strains [59-62].

3 MCA is applied to improve lysine production and to quantify the modifications

4 imposed. The metabolic pathway for lysine production for Corynebacterium species is

5 represented in Figure 4. As can be seen, the synthesis has successive catalysed

6 reactions. First, L-aspartate is activated by aspartokinase (ASK) and reduced by

7 aspartate semialdehyde dehydrogenase (ASD). Dihydrodipicolinate synthase (DHPS)

8 and dihydrodipicolinate reductase (DHPR) catalyse the subsequent steps in the pathway

9 [59, 60]. At this point, L-tetrahydrodipicolinate (THDP) can be transformed into 1-

10 lysine by two different ways: the dehydrogenase pathway (catalysed by

11 diaminopimelate dehydrogenase (DAPDH)) or the succinylase pathway, that operate at

12 the same time $[62,63]$. L-lysine is then obtained from D, L-diaminopimelate

13 decarboxylation by diaminopimelate decarboxylase (DAPDC) [59, 60].

14 The kinetic expressions are not projected to ASD and DHPR, due to the fact that they 15 operate near equilibrium [64]. For ASK, the production of aspartate semialdehyde 16 (ASA) is represented by the specific rate of the enzyme catalysed reaction, according to 17 equation $17[64,65]$.

18

$$
\begin{aligned}
\mathrm{r}_{\mathrm{ASA}}^{\mathrm{ASK}}=\frac{v_{\max }\left(\mathrm{c}_{\mathrm{ASP}} \mathrm{c}_{\mathrm{ATP}}-\frac{\mathrm{c}_{\mathrm{ADP}} \mathrm{C}_{\mathrm{BAP}}}{\mathrm{K}_{\text {eq,ASK }}}\right)}{\mathrm{K}_{\mathrm{ASP}} \mathrm{K}_{\mathrm{ATP}}}+\mathrm{K}_{\mathrm{ATP} \mathrm{C}_{\mathrm{ASP}}+\mathrm{K}_{\mathrm{ASP}} \mathrm{c}_{\mathrm{ATP}}+\mathrm{c}_{\mathrm{ASP}} \mathrm{c}_{\mathrm{ATP}}+\frac{\mathrm{K}_{\mathrm{ASP}} \mathrm{K}_{\mathrm{ATP}} \mathrm{c}_{\mathrm{ADP}}}{\mathrm{K}_{\mathrm{ADP}}}+\frac{\mathrm{K}_{\mathrm{ASP}} \mathrm{K}_{\mathrm{ATP}} \mathrm{C}_{\mathrm{BAP}}}{\mathrm{K}_{\mathrm{BAP}}}+\frac{\mathrm{K}_{\mathrm{ASP}} \mathrm{K}_{\mathrm{ATP}} \mathrm{C}_{\mathrm{ADP}} \mathrm{C}_{\mathrm{BAP}}}{\mathrm{K}_{\mathrm{ADP}} \mathrm{K}_{\mathrm{BAP}}}} \\
\times \frac{1}{1+\mathrm{L}_{\mathrm{Lys}-\mathrm{Thr}}\left(1+\frac{\mathrm{c}_{\mathrm{Lys}}}{\mathrm{K}_{\mathrm{Lys}}}\right)^{8}}
\end{aligned}
$$

19

20 Where $\mathrm{L}_{\mathrm{Lys}-\mathrm{Thr}}$ is the inhibition term by lysine and threonine and $\mathrm{c}_{\mathrm{BAP}}$ is defined in equation $18[64,65]$. 


$$
\mathrm{c}_{\mathrm{BAP}}=\frac{\mathrm{c}_{\mathrm{ASA}} \mathrm{c}_{\mathrm{NADP}} \mathrm{c}_{\mathrm{Pi}}}{\mathrm{K}_{\mathrm{eq}, \mathrm{ASD}} \mathrm{c}_{\mathrm{NADPH}} \mathrm{c}_{\mathrm{H}^{+}}}
$$

1

2 For DHPS, for the production of L-dihydrodipicolinate (DHP), is represented in 3 equation $19[64,65]$.

4

5

$$
\mathrm{r}_{\mathrm{DHP}}^{\text {DHPS }}=\frac{v_{\mathrm{max}}\left(\mathrm{c}_{\mathrm{Pyr}} \mathrm{c}_{\mathrm{ASA}}\right)}{\mathrm{K}_{\mathrm{m}, \mathrm{ASA}} \mathrm{c}_{\mathrm{Pyr}}+\mathrm{K}_{\mathrm{m}, \mathrm{Pyr}} \mathrm{c}_{\mathrm{ASA}}+\mathrm{c}_{\mathrm{Pyr}} \mathrm{c}_{\mathrm{ASA}}+\mathrm{c}_{\mathrm{DHP}}\left(\frac{\mathrm{K}_{\mathrm{m}, \mathrm{Pyr}} \mathrm{K}_{\mathrm{i}, \mathrm{ASA}}}{\mathrm{K}_{\mathrm{i}, \mathrm{DHP}}}+\mathrm{c}_{\mathrm{ASA}} \frac{\mathrm{K}_{\mathrm{m}, \mathrm{Pyr}}}{\mathrm{K}_{\mathrm{i}, \mathrm{DHP}}}\right)}
$$

6 Where $\mathrm{c}_{\mathrm{DHP}}$ is defined in equation $20[64,65]$.

7

8

$$
c_{\mathrm{DHP}}=\frac{\mathrm{c}_{\mathrm{THDP}} \mathrm{c}_{\mathrm{NADP}^{+}}}{\mathrm{K}_{\mathrm{eq}, \mathrm{DHPR}} \mathrm{C}_{\mathrm{NADPH}} \mathrm{C}_{\mathrm{H}^{+}}}
$$

9 Concerning DADPH, for the production of D, L-diaminopimelate (DAP) the specific rate of the enzyme catalysed reaction is calculated through equation $21[64,65]$.

$$
\mathrm{r}_{\mathrm{DAP}}^{\mathrm{DADPH}}=\frac{v_{\max }}{\left(1+\frac{\mathrm{K}_{\mathrm{NADPH}}}{c_{\mathrm{NADPH}}}\right)\left(1+\frac{\mathrm{K}_{\mathrm{NH}_{4}^{+}}}{c_{\mathrm{NH}_{4}^{+}}}\right)\left(1+\frac{\mathrm{K}_{\mathrm{THDP}}}{c_{\mathrm{THDP}}}\right)}
$$

13 For DAPDC, the production of 1-lysine (Lys), was found to follow a Michaelis-Menten 14 kinetics, resulting in equation $22[64,65]$.

$$
\mathrm{r}_{\mathrm{LyS}}^{\mathrm{DAPDC}}=\frac{v_{\max } \mathrm{c}_{\mathrm{DAP}}}{\mathrm{K}_{\mathrm{m}, \mathrm{DAP}}+\mathrm{c}_{\mathrm{DAP}}}
$$

17 The first step of the reaction is the rate limiting step, consequently the control is mainly exerted by ASK [64]. The kinetic parameters can be estimated by different software [64]: CONTROL [21] and MetaCon [22]. The first uses the matrix method to calculate control coefficients [21] and MetaCon allows the calculation of algebraic expressions for the control coefficients [22]. The application of MCA for the production of desirable 
1 industrial products is a future proposition. To achieve higher concentrations of products,

2 it is necessary to use simulation to evaluate the magnitude of the changes applied [16].

3 Moreover, the productivity of 1-lysine can be enhanced through genetic engineering

4 techniques, such as coordinated gene overexpression [61].

5

6 3.4. GLYCEROL PRODUCTION

7 Glycerol is a by-product commonly formed by Saccharomyces cerevisiae during 8 alcoholic fermentation [66]. It is used to synthetize products like lubricants and 9 cosmetics [67] and it is also used as an antifreeze in chemical industry [68]. This promising product is synthetized by the reduction of dihydroxyacetone phosphate (DHAP) to glycerol-3-phosphate, by glycerol-3-phosphate dehydrogenase (GPD).

12 Glycerol-3-phosphate is then dephosphorylated to glycerol by glycerol-3-phosphatase (GPP) (Figure 5) [66, 67]. S. cerevisiae produces this compound in response to osmotic stress or anaerobiosis. The quantity of glycerol naturally produced is small, therefore, research has been made to direct the sugar metabolism to glycerol production [67]. The increase in glycerol production was accomplished by the sulfite process and by the application of recombinant DNA technology. In the sulfite process, sulfite is added to the fermentation process and it stays connected with acetaldehyde. With this bond the acetaldehyde is not able to be an electron acceptor in the reoxidation of NADH. The $\mathrm{NADH}$ is then reoxidized but in glycerol production [67]. When using engineered strains it was found that glycerol is accumulated intracellularly. Using MCA, it was found that the glycerol efflux is the rate limiting step of this reaction [66]. Other recombinant techniques applied were the reduction of pyruvate decarboxylase expression and deletion of alcohol dehydrogenase genes [67]. 
1 Cronwright et al. [69] determined a model with MCA and concluded that several

2 parameters affect glycerol production, and that some parameters may have a certain

3 effect when altered in the beginning of the fermentation process and the same parameter

4 may not affect the fermentation in the end of the process. This shows that despite the

5 fact that MCA is a powerful tool, not everything can be predicted [69].

6

\section{CONCluding REMARKS AND Future OUTLOOK}

8 ME applies multidisciplinary techniques, including computer and experimentation, 9 allowing the study of cell dynamics and function. This knowledge enables the 10 modification of microorganisms in order to improve the productivity of a particular metabolic product. In this work it was presented the application of MCA to study the metabolic pathways of microorganisms. This strategy allows to identify which are the enzymes that have higher control coefficients, in order to control the metabolic performance of the organisms. The enzymes and the pathways involved are the key to improve the common methods and applications.

Complete success in ME will only be achieved if the changes in metabolism can accomplish industrial application. However, although the study of kinetics is a slow process, this technique is the one that helps the reliable design of the desired strain, with the highest metabolic performance and, thus the highest productivity. To improve the knowledge on enzyme kinetics, at a large scale, mathematical simulation is a required tool.

\section{REFERENCES}

24 [1] Raab RM, Tyo K, Stephanopoulos G. Metabolic Engineering. In: Nielsen J, editor. Biotechnology for the Future: Springer Berlin Heidelberg. 2005; pp. 1-17. 
1 [2] Christensen B, Nielsen J. Metabolic network analysis. In: Sonnleitner B, editor.

2 Bioanalysis and Biosensors for Bioprocess Monitoring: Springer Berlin Heidelberg. 3 2000; pp. 209-31.

4 [3] Anesiadis N, Cluett WR, Mahadevan R. Dynamic metabolic engineering for 5 increasing bioprocess productivity. Metab Eng 2008; 10(5): 255-66.

6 [4] Wang L, Birol I, Hatzimanikatis V. Metabolic control analysis under 7 uncertainty: framework development and case studies. Biophys J 2004; 87(6): 3750-63.

8 [5] Shimizu H. Metabolic engineering - Integrating methodologies of molecular 9 breeding and bioprocess systems engineering. J Biosci Bioeng 2002; 94(6): 563-73. [6] Stephanopoulos G, Stafford DE. Metabolic engineering: a new frontier of chemical reaction engineering. Chem Eng Sci 2002; 57(14): 2595-602.

[7] Mauch K, Arnold S, Reuss M. Dynamic sensitivity analysis for metabolic systems. Chem Eng Sci 1997; 52(15): 2589-98.

[8] Klapa MI, Quackenbush J. The quest for the mechanisms of life. Biotechnol Bioeng 2003; 84(7): 739-42.

[9] Stafford DE, Stephanopoulos G. Metabolic engineering as an integrating platform for strain development. Curr Opin Microbiol 2001; 4(3): 336-40.

[10] Shimizu K. Toward systematic metabolic engineering based on the analysis of metabolic regulation by the integration of different levels of information. Biochem Eng J 2009; 46(3): 235-51.

[11] Koffas M, Roberge C, Lee K, Stephanopoulos G. Metabolic engineering. Annu Rev Biomed Eng 1999; 1: 535-57.

[12] Stephanopoulos G, Aristidou A, Nielsen J. Metabolic Control Analysis. In: Stephanopoulos G, Aristidou A, Nielsen J, editors. Metabolic Engineering: Principles and Methodologies: Academic Press. 1998; pp. 464-533.

[13] Moreno-Sánchez R, Saavedra E, Rodríguez-Enríquez S, Olín-Sandoval V. Metabolic control analysis: a tool for designing strategies to manipulate metabolic pathways. J Biomed Biotechnol 2008; 2008: 1-30.

[14] Franco-Lara E, Weuster-Botz D. Application of fuzzy-logic models for metabolic control analysis. J Theor Biol 2007; 245(3): 391-9.

[15] Fell DA, Thomas S. Physiological Control of Metabolic Flux: the Requirement for Multisite Modulation. Biochem J 1995; 311: 35-9.

[16] Copeland WB, Bartley BA, Chandran D, Galdzicki M, Kim KH, Sleight SC, et al. Computational tools for metabolic engineering. Metab Eng 2012; 14(3): 270-80. 
1 [17] Sauro HM, Fell DA. SCAMP: A metabolic simulator and control analysis 2 program. Math Comput Model 1991; 15(12): 15-28.

3 [18] Cornish-Bowden A, Hofmeyr JH. MetaModel: a program for modelling and 4 control analysis of metabolic pathways on the IBM PC and compatibles. Comput Appl 5 Biosci 1991; 7(1): 89-93.

6 [19] Mendes P. GEPASI: a software package for modelling the dynamics, steady 7 states and control of biochemical and other systems. Comput Appl Biosci 1993; 9(5): $8 \quad 563-71$.

9 [20] Kell DB. Systems biology, metabolic modelling and metabolomics in drug discovery and development. Drug Discov Today 2006; 11(23-24): 1085-92.

[21] Letellier T, Reder C, Mazat J-P. CONTROL: software for the analysis of the control of metabolic networks. Comput Appl Biosci 1991; 7(3): 383-90.

[22] Thomas S, Fell D. MetaCon - A Computer Program for the Algebraic Evaluation of Control Coefficients of Metabolic Networks. In: Schuster S, Rigoulet M, Ouhabi R, Mazat J-P, editors. Modern Trends in Biothermokinetics: Springer US. 1993; pp. 473-8. [23] Heijnen JJ. Metabolic Control Analysis. In: Smolke CD, editor. $1^{\text {st }}$ ed. The Metabolic Pathway Engineering Handbook: Fundamentals: CRC Press, Taylor \& Francis Group. 2010; pp. 16.1-.30.

[24] Tun K, Dhar PK, Palumbo MC, Giuliani A. Metabolic pathways variability and sequence/networks comparisons. BMC Bioinformatics 2006; 7(1): 24.

[25] Bayram M, Yildirim N. Metabolic control analysis of trio enzymes system. Appl Math Comput 2005; 170(2): 948-57.

[26] Funahashi A, Morohashi M, Kitano H, Tanimura N. CellDesigner: a process diagram editor for gene-regulatory and biochemical networks. Biosilico 2003; 1(5): $159-62$.

[27] Bayram M. Automatic analysis of the control of metabolic networks. Comput Biol Med 1996; 26(5): 401-8.

[28] Caspi R, Altman T, Dale JM, Dreher K, Fulcher CA, Gilham F, et al. The MetaCyc database of metabolic pathways and enzymes and the BioCyc collection of pathway/genome databases. Nucleic Acids Res 2010; 38: D473-9.

[29] Wang L, Hatzimanikatis V. Metabolic engineering under uncertainty. I: Framework development. Metab Eng 2006; 8(2): 133-41.

[30] Fell DA. Increasing the flux in metabolic pathways: A metabolic control analysis perspective. Biotechnol Bioeng 1998; 58(2-3): 121-4. 
1 [31] Heinrich R, Schuster S. The modelling of metabolic systems. Structure, control 2 and optimality. Biosystems 1998; 47(1-2): 61-77.

3 [32] Kholodenko BN, Schuster S, Garcia J, Westerhoff HV, Cascante M. Control 4 analysis of metabolic systems involving quasi-equilibrium reactions. BBA-Gen Subjects $5 \quad 1998 ; 1379(3): 337-52$.

6 [33] Visser D, Heijnen JJ. The mathematics of metabolic control analysis revisited. $7 \quad$ Metab Eng 2002; 4(2): 114-23.

8 [34] Cornish-Bowden A. Metabolic Control Analysis in Theory and Practice. In: 9 Bittar EE, editor. Advances in Molecular and Cell Biology: Elsevier. 1995; pp. 21-64. [35] Schuster S, Heinrich R. The definitions of metabolic control analysis revisited. Biosystems 1992; 27(1): 1-15.

[36] Shiraishi F, Sriyudthsak K, Suzuki Y. Calculation errors of time-varying flux control coefficients obtained from elasticity coefficients by means of summation and connectivity theorems in metabolic control analysis. Math Biosci 2010; 223(2): 105-14. [37] Morandini P. Rethinking metabolic control. Plant Sci 2009; 176(4): 441-51. [38] Heijnen JJ, van Gulik WM, Shimizu H, Stephanopoulos G. Metabolic flux control analysis of branch points: an improved approach to obtain flux control coefficients from large perturbation data. Metab Eng 2004; 6(4): 391-400.

[39] Sauro HM, Bergmann FT. Chapter 12 - Software Tools for Systems Biology. In: Edison TL, Douglas AL, editors. Systems Biomedicine. San Diego: Academic Press. 2010; pp. 289-314.

22 [40] Cascante M, Boros LG, Comin-Anduix B, de Atauri P, Centelles JJ, Lee PWN. Metabolic control analysis in drug discovery and disease. Nat Biotech 2002; 20(3): 2439.

[41] Schuster S. Use and Limitations of Modular Metabolic Control Analysis in Medicine and Biotechnology. Metab Eng 1999; 1(3): 232-42. [42] Moreno-Sánchez R, Saavedra E, Rodríguez-Enríquez S, Gallardo-Pérez JC, Quezada H, Westerhoff HV. Metabolic control analysis indicates a change of strategy in the treatment of cancer. Mitochondrion 2010; 10(6): 626-39. [43] Özbayraktar FBK, Ülgen KÖ. Drug target identification in sphingolipid metabolism by computational systems biology tools: Metabolic control analysis and metabolic pathway analysis. J Biomed Inform 2010; 43(4): 537-49. 
1 [44] Hornberg J, Bruggeman F, Bakker B, Westerhoff H. Metabolic control analysis

2 to identify optimal drug targets. In: Boshoff H, Barry C, III, editors. Systems Biological

3 Approaches in Infectious Diseases: Birkhäuser Basel. 2007; pp. 171-89.

4 [45] Hornberg JJ, Bruggeman FJ, Binder B, Geest CR, de Vaate AJMB, Lankelma J,

5 et al. Principles behind the multifarious control of signal transduction. FEBS J 2005;

6 272(1): 244-58.

7 [46] Trombetta M, Boselli L, Cretti A, Calì A, Vettore M, Caruso B, et al. Type 2

8 diabetes mellitus: A disease of the governance of the glucose-insulin system: An

9 experimental metabolic control analysis study. Nutr Metab Cardiovas 2013; 23(1): 231030.

[47] Thykaer J, Nielsen J. Metabolic engineering of $\beta$-lactam production. Metab Eng 2003; 5(1): 56-69.

[48] Jørgensen H, Nielsen J, Villadsen J, Møllgaard H. Analysis of penicillin V chrysogenum. Appl Microbiol Biotechnol 1995; 43(1): 123-30.

[49] Nielsen J. The role of metabolic engineering in the production of secondary metabolites. Curr Opin Microbiol 1998; 1(3): 330-6.

[50] Nasution U, van Gulik WM, Ras C, Proell A, Heijnen JJ. A metabolome study of the steady-state relation between central metabolism, amino acid biosynthesis and penicillin production in Penicillium chrysogenum. Metab Eng 2008; 10(1): 10-23.

[51] Pissara PN, Nielsen J, Bazin MJ. Pathway kinetics and metabolic control analysis of a high-yielding strain of Penicillium chrysogenum during fed batch cultivations. Biotechnol Bioeng 1996; 51(2): 168-76.

[52] Nielsen J, Jørgensen HS. Metabolic control analysis of the penicillin biosynthetic pathway in a high-yielding strain of Penicillium chrysogenum. Biotechnol Progr 1995; 11(3): 299-305.

[53] Nielsen J, Jørgensen HS. A kinetic model for the penicillin biosynthetic pathway in Penicillium chrysogenum. Control Eng Pract 1996; 4(6): 765-71.

[54] Theilgaard HA, Nielsen J. Metabolic control analysis of the penicillin biosynthetic pathway: the influence of the lld-ACV:bisACV ratio on the flux control. Anton Leeuw Int J G 1999; 75(1): 145-54.

[55] Peñalva MA, Rowlands RT, Turner G. The optimization of penicillin biosynthesis in fungi. Trends Biotechnol 1998; 16(11): 483-9. 
1 [56] van den Berg MA. Functional characterisation of penicillin production strains. 2 Fungal Biol Rev 2010; 24(1-2): 73-8.

3 [57] Krämer R. Genetic and physiological approaches for the production of amino 4 acids. J Biotechnol 1996; 45(1): 1-21.

5 [58] Galili G, Tang G, Zhu X, Gakiere B. Lysine catabolism: a stress and 6 development super-regulated metabolic pathway. Curr Opin Plant Biol 2001; 4(3): 26176

8 [59] Becker J, Zelder O, Häfner S, Schröder H, Wittmann C. From zero to hero9 Design-based systems metabolic engineering of Corynebacterium glutamicum for 1lysine production. Metab Eng 2011; 13(2): 159-68.

[60] Leuchtenberger W, Huthmacher K, Drauz K. Biotechnological production of amino acids and derivatives: current status and prospects. Appl Microbiol Biotechnol 2005; 69(1): 1-8.

[61] Koffas MAG, Jung GY, Stephanopoulos G. Engineering metabolism and product formation in Corynebacterium glutamicum by coordinated gene overexpression. Metab Eng 2003; 5(1): 32-41.

[62] Becker J, Wittmann C. Systems and synthetic metabolic engineering for amino acid production - the heartbeat of industrial strain development. Curr Opin Biotechnol 2012; 23(5): 718-26.

[63] Schrumpf B, Schwarzer A, Kalinowski J, Pühler A, Eggeling L, Sahm H. A functionally split pathway for lysine synthesis in Corynebacterium glutamicum. J Bacteriol 1991; 173(14): 4510-6.

[64] Yang C, Hua Q, Shimizu K. Development of a kinetic model for 1-lysine biosynthesis in Corynebacterium glutamicum and its application to metabolic control analysis. J Biosci Bioeng 1999; 88(4): 393-403.

[65] Hua Q, Yang C, Shimizu K. Metabolic control analysis for lysine synthesis using Corynebacterium glutamicum and experimental verification. J Biosci Bioeng 2000; 90(2): 184-92.

[66] Cordier H, Mendes F, Vasconcelos I, François JM. A metabolic and genomic study of engineered Saccharomyces cerevisiae strains for high glycerol production. Metab Eng 2007; 9(4): 364-78.

[67] Overkamp KM, Bakker BM, Kötter P, Luttik MA, van Dijken JP, Pronk JT. Metabolic engineering of glycerol production in Saccharomyces cerevisiae. Appl 
1 [68] Compagno C, Boschi F, Ranzi BM. Glycerol production in a triose phosphate

2 isomerase deficient mutant of Saccharomyces cerevisiae. Biotechnol Progr 1996; 12(5):

$3591-5$.

4 [69] Cronwright GR, Rohwer JM, Prior BA. Metabolic control analysis of glycerol 5 synthesis in Saccharomyces cerevisiae. Appl Environ Microbiol 2002; 68(9): 4448-56.

6 [70] Chatziioannou A, Kolisis FN, Papadodima O, Valavanis I, Pilalis E. Metabolic 7 Engineering - Bioinformatics. Institute of Biology, Medicinal Chemistry \& 8 Biotechnology

9 http://www.eie.gr/nhrf/institutes/ibrb/programmes/metabolicengineering-en.html

10 (Accessed January 15, 2014).

11

12 
2

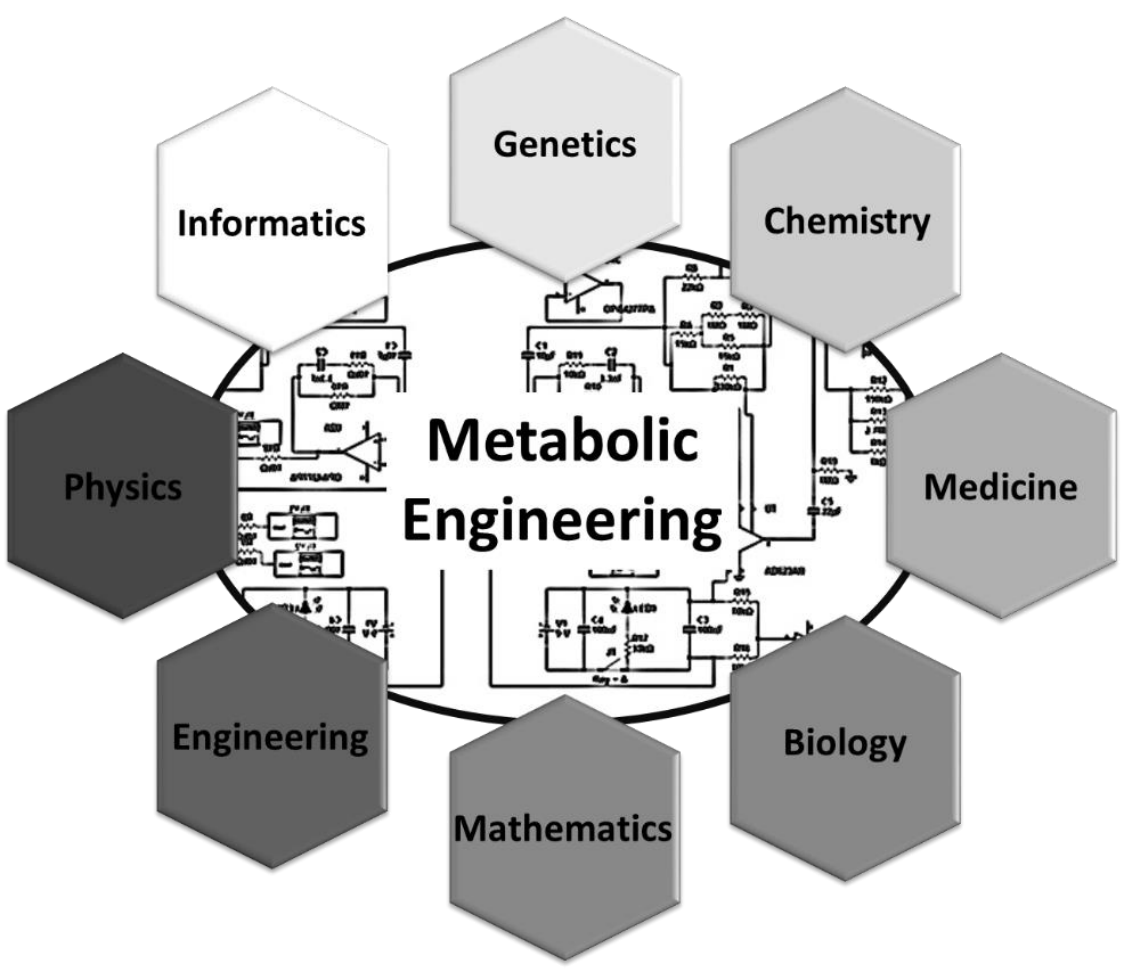

3 Figure 1 - Schematic representation of Metabolic Engineering multidisciplinarity 4 (adapted from [70]). 


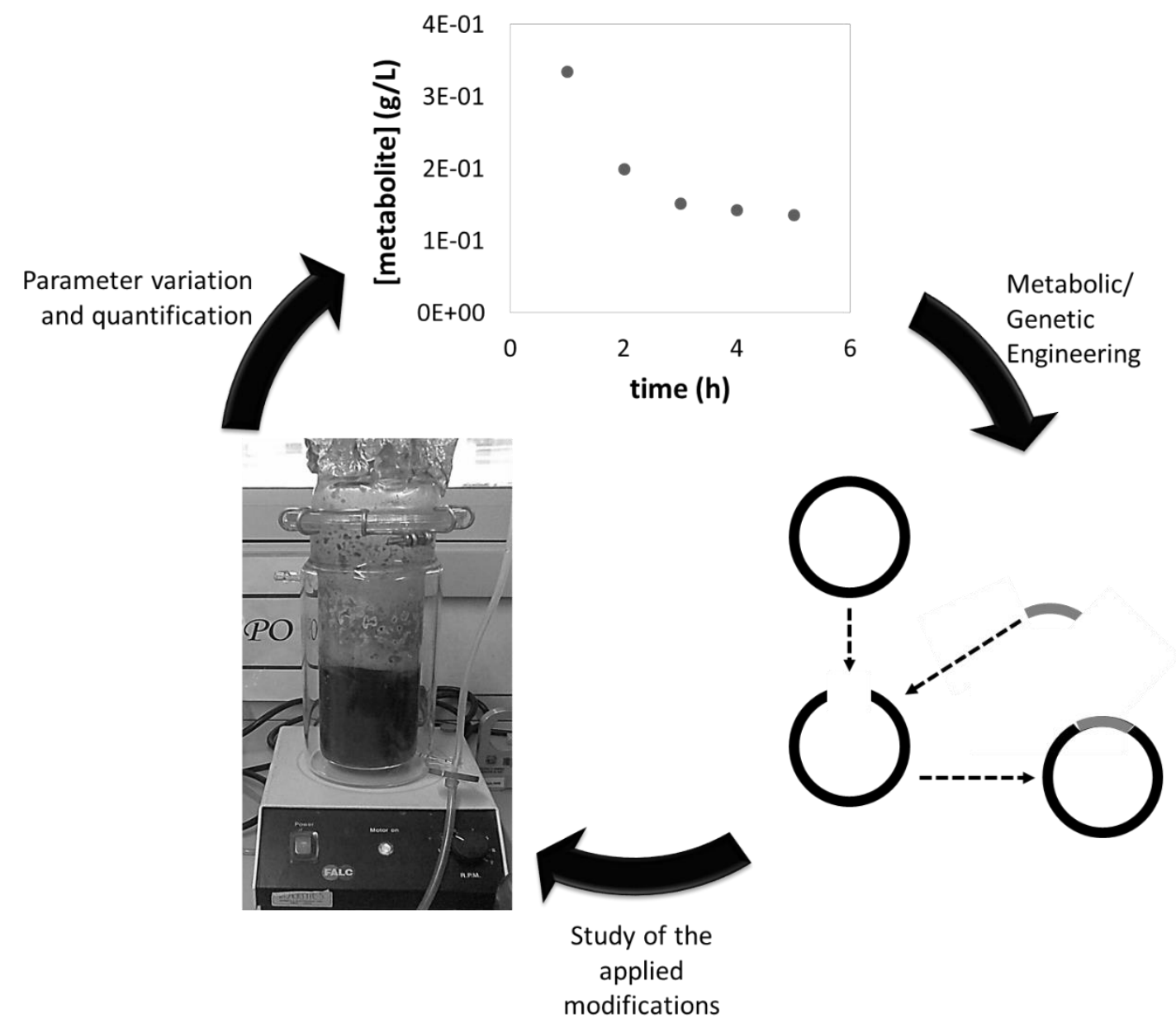

2 Figure 2-Schematic representation of a strategy MCA. 


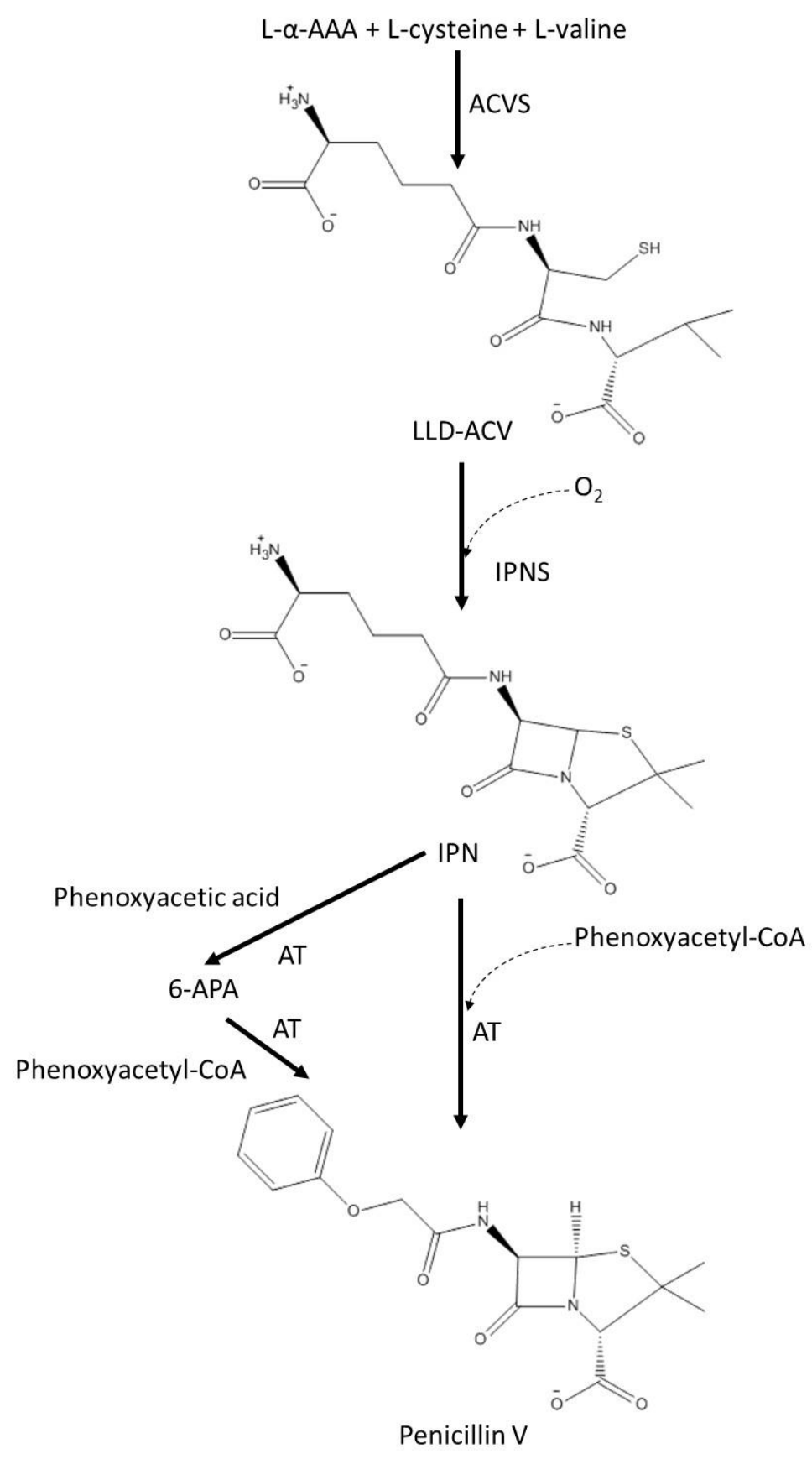

Figure 3 - Metabolic pathway for penicillin V synthesis (adapted from [51]). 
<smiles>N[C@@H](CC(=O)[O-])C(=O)[O-]</smiles>

L-aspartate

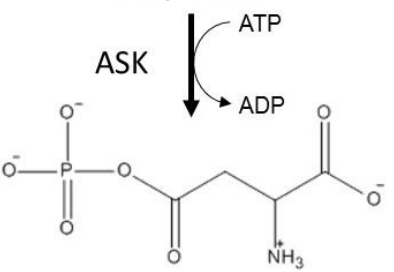

$\beta$-aspartylphosphate
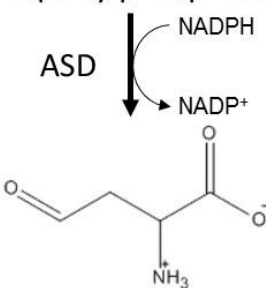

L-aspartate semialdehyde

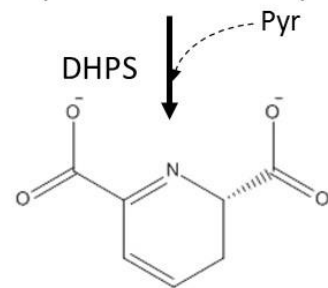

L-dihydrodipicolinate

DHPR<smiles>O=C(O)C1=N[C@H](C(=O)[O-])CCC1</smiles>

L-tetrahydrodipicolinate

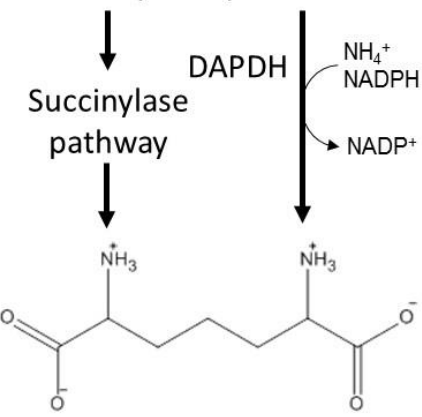

D,L-diaminopimelate

DAPDC ${ } \mathrm{CO}_{2}$<smiles>NCCCCC(N)C(=O)[O-]</smiles>

L-lysine

2 Figure 4 - Metabolic pathway for l-lysine production (adapted from [64, 65]). 


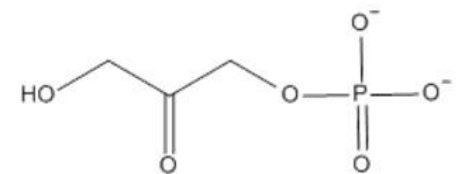

Dihydroxyacetone phosphate
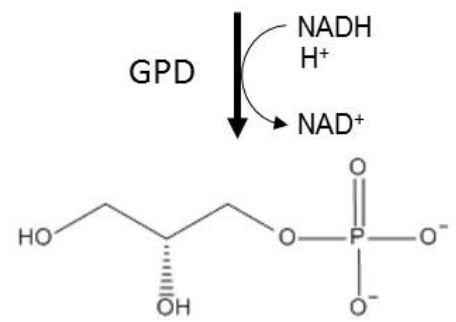

Grycerol-3-phosphate

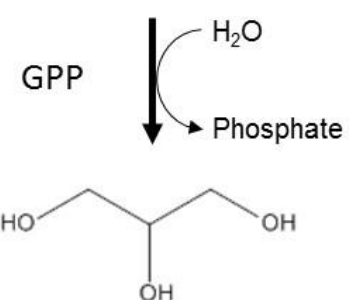

1

Glycerol

2 Figure 5 - Metabolic pathway for glycerol production (adapted from [67]). 